\title{
Effect of age on dental plaque deposition and its control by ultrasonic scaling, dental hygiene chew, and chlorhexidine $(0.2 \% \mathrm{w} / \mathrm{v})$ in dogs
}

\author{
Nishiswapna Garanayak ${ }^{1}$, Manoranjan Das ${ }^{1}$, Ramesh Chandra Patra ${ }^{1}$, Sangram Biswal ${ }^{2}$ and Susen Ku Panda ${ }^{3}$ \\ 1. Department of Clinical Medicine, Ethics and Jurisprudence, College of Veterinary Science and Animal Husbandry, \\ Orissa University of Agriculture and Technology, Bhubaneswar, Odisha, India; 2. Department of Epidemiology and \\ Preventive Medicine, College of Veterinary Science and Animal Husbandry, Orissa University of Agriculture and \\ Technology, Bhubaneswar, Odisha, India; 3. Department of Veterinary Pathology, College of Veterinary Science and \\ Animal Husbandry, Orissa University of Agriculture and Technology, Bhubaneswar, Odisha, India. \\ Corresponding author: Nishiswapna Garanayak, e-mail: littlegaranayak@gmail.com \\ Co-authors: MD: dr_mrdas@rediffmail.com, RCP: rcpatra@gmail.com, SB: drsangrambiswal@gmail.com,
} SKP: drsusen_panda@yahoo.com

Received: 02-07-2019, Accepted: 19-10-2019, Published online: 28-11-2019

doi: www.doi.org/10.14202/vetworld.2019.1872-1876 How to cite this article: Garanayak N, Das M, Patra RC, Biswal S, Panda SK (2019) Effect of age on dental plaque deposition and its control by ultrasonic scaling, dental hygiene chew, and chlorhexidine $(0.2 \% \mathrm{w} / \mathrm{v})$ in dogs, Veterinary World, $12(11): 1872-1876$.

\begin{abstract}
Background and Aim: Periodontitis is the most prevalent inflammatory dental disease caused by a lack of oral hygiene measures in domestic animals. The periodontal disease complex arises as a result of bacterial biofilm deposition termed as plaque on the tooth surface. Lack of cleaning measures either mechanical or chemical credit for the condition. The present study was conducted to screen the animals for the presence of plaque deposition, gingivitis, along with various control measures for the same.

Materials and Methods: Thirty-two dogs of different age groups were evaluated for the presence of plaque and gingivitis by scoring method to estimate the extent of severity. Scaling of the tooth surface was done by ultrasonic scaling machine to remove the plaques, and the animals were divided into four treatment groups to study the effects of dental hygiene chew and chlorhexidine for control of plaque.

Results: Present study revealed $71.87 \%$ and $34.37 \%$ of the screened animals were having plaque deposition and varied degrees of gingivitis respectively. A positive coefficient of correlation $(r)$ of $0.89(p<0.05)$ between advancing age and plaque deposition and $0.85(\mathrm{p}<0.05)$ between age and level of gingivitis was obtained. Two groups receiving dental chew and $0.2 \% \mathrm{w} / \mathrm{v}$ chlorhexidine showed lower plaque deposits, and the fourth treatment group receiving both dental chew and chlorhexidine showed 100\% animals remained free from fresh plaque deposits.
\end{abstract}

Conclusion: The present study showed a strong positive relationship between age and plaque deposition and gingivitis. The study also showed that oral hygiene measures such as use of dental hygiene chew and chlorhexidine application can reduce plaque deposition and periodontitis in domesticated canines.

Keywords: chlorhexidine, dental chew, dental plaque, dog, scaling.

\section{Introduction}

The oral cavity of the animal is the gateway to the digestive system. It is the foremost important organ consisting of varied degrees of anatomical structures. Periodontium is one of the major structures comprised of tooth and its supporting structures such as gingiva alveolar bone, periodontal ligament, and cementum [1]. Periodontitis is the most prevalent and unapparent inflammatory dental disease caused by bacterial plaque on the periodontium [2]. Early diagnosis of the oral infection at the stage of gingivitis and its proper treatment can reverse the damage. The disease has been reported to have many distance implications in the body organs $[3,4]$. The correlation

Copyright: Garanayak, et al. Open Access. This article is distributed under the terms of the Creative Commons Attribution 4.0 International License (http://creativecommons.org/licenses/ by/4.0/), which permits unrestricted use, distribution, and reproduction in any medium, provided you give appropriate credit to the original author(s) and the source, provide a link to the Creative Commons license, and indicate if changes were made. The Creative Commons Public Domain Dedication waiver (http:// creativecommons.org/publicdomain/zero/1.0/) applies to the data made available in this article, unless otherwise stated. between increasing age and oral disorders has already been established based on prevalence and severity studies. A large number of domestic carnivores (80\%) were reported as being infected by the disease after the age of 2 years [5-7]. Newly formed calculus covered with dental plaque accounted for the advancement of the disease process leading to initiation of inflammatory cascades causing gingivitis [8].

Veterinary dentistry emphasized on importance of plaque and calculus removal from the tooth crown, gingival sulcus, and root surfaces. The removal can be done by mechanical (Brushing, scaling, ultrasonic scaling, and dental chew) and chemical (chlorhexidine gluconate, and special diet) means for the prevention and control of periodontal disease $[1,4,5,9,10]$. The use of dental chews of varied shapes and sizes with or without an anti-calculus agent has been demonstrated as one of the easiest methods for removal of supragingival plaque accumulation [5,8,10-12].

Although a large number of canine companions are present in the urban and semi-urban areas of Odisha, no study has been focused on their oral 
hygiene and status of periodontal affections. Moreover no trials have been made in the state of Odisha regarding evaluation of plaque status in domestic dogs and its removal and effective management.

This study aimed to screen the animals for the presence of plaque deposition, gingivitis, and their subsequent control by use of scaling, dental chew, and chlorhexidine treatment.

\section{Materials and Methods}

\section{Ethical approval}

The study was approved by Dean, College of Veterinary Science \& AH, OUAT, Odisha, India. All ethical guidelines were followed during the study.

\section{Area of the study}

The study was conducted at the Department of Clinical Medicine, Ethics and Jurisprudence, College of Veterinary Science and Animal Husbandry (AH), Orissa University of Agriculture and Technology (OUAT), Bhubaneswar. The collection of samples and selection of animals were done from Teaching Veterinary Clinical Complex of College of Veterinary Science and AH, OUAT, Bhubaneswar, private pet clinics of Bhubaneswar city and nearby areas.

\section{Scoring of gingivitis and plaque deposition}

The animals were screened for visible plaque deposition on the tooth surface, and scoring was done as described by Clarke et al. [8] with slight modification. Total visible tooth surface area (mesial, buccal, labial, lingual, and distal) covered by plaque was taken into consideration for the scoring pattern (Figures-1 and 2). Probing was done to assess tooth mobility and loosening. The details of the scoring pattern are described in Table-1.

The severity of gingivitis was measured according to previous research methodology with slight modification [12]. Visible changes in the gingival were taken into consideration for the scoring of gingivitis. The total surface area affected and reddening of the mucosa was assessed. The details of the scoring pattern are described in Table-2.

\section{Ultrasonic scaling of the tooth surface}

Plaque removal was done using Ultrasonic Scaler (Brand-DTE D1) by scaling of the teeth surface under the influence of mild anesthesia or sedation [13]. The dogs after a complete cleaning of the plaques deposits were regarded as "Clean tooth model" as described by Hennet et al. [14].

\section{Experimental design}

A parallel, cross-over design clinical study on the accumulation of plaques following complete scaling of the tooth surface was done. Out of screened 32 numbers of dogs, 16 numbers of client-owned dogs were selected randomly for the study. Sixteen numbers of dogs after the preparation of clean tooth model were grouped into four trial categories randomly.

Group - 1: Animals were given normal food without any kind of dental care measures. They are

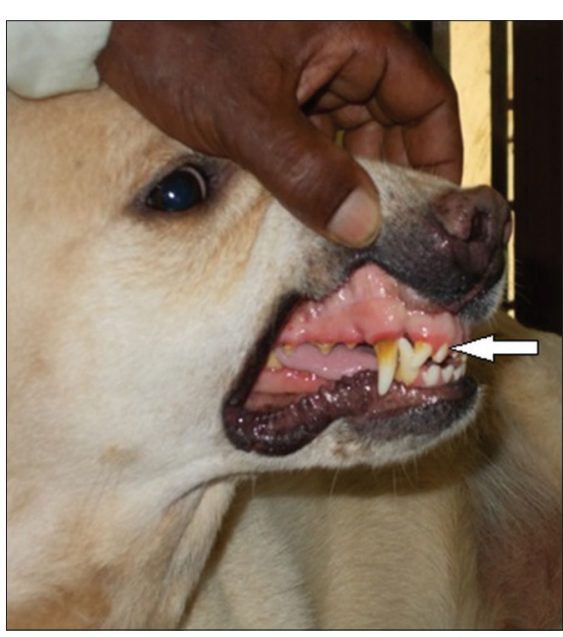

Figure-1: Visual assessment of plaque deposition and gingivitis (Score 2).

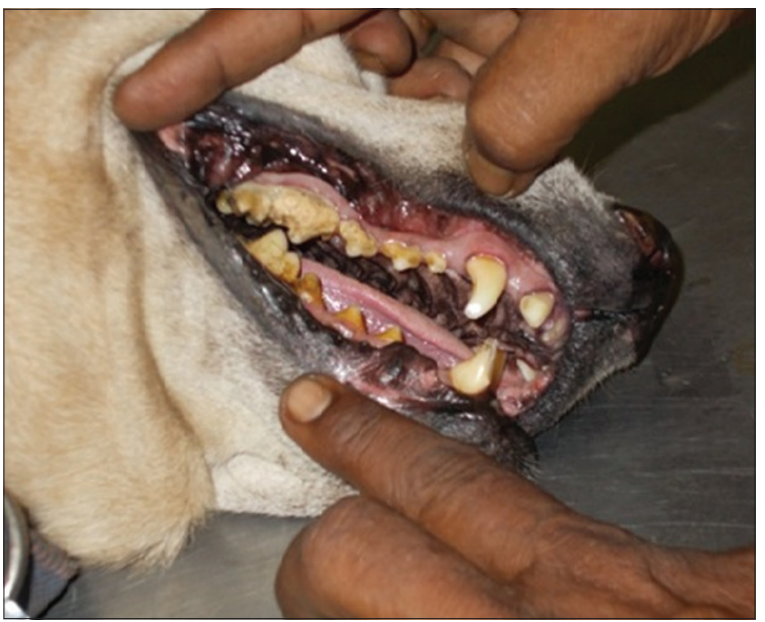

Figure-2: Visual assessment of plaque (plaque deposition Score 4).

Table-1: Scoring criteria for the plaque deposition.

\begin{tabular}{lll}
\hline $\begin{array}{l}\text { Assigned } \\
\text { score }\end{array}$ & $\begin{array}{l}\text { Amount of plaque } \\
\text { deposition }\end{array}$ & $\begin{array}{l}\text { Coverage of } \\
\text { plaque }\end{array}$ \\
\hline 0 & No detectable plaque & $\begin{array}{l}\text { Nil } \\
<24 \% \text { of the tooth } \\
\text { surface }\end{array}$ \\
2 & Scattered plaque & $\begin{array}{l}25-49 \% \text { of the tooth } \\
\text { surface }\end{array}$ \\
3 & Scattered plaque & $\begin{array}{l}50-74 \% \text { of the tooth } \\
\text { surface } \\
\text { More than } 75 \% \text { of the } \\
\text { tooth surface }\end{array}$ \\
\hline
\end{tabular}

Table-2: Scoring criteria for level of gingivitis.

\begin{tabular}{|c|c|}
\hline $\begin{array}{l}\text { Assigned } \\
\text { score }\end{array}$ & Level of gingivitis \\
\hline 0 & No gingivitis \\
\hline $1(+)$ & Incipient gingivitis (slight red, swollen) \\
\hline $2(++)$ & Mild gingivitis (red, swollen) \\
\hline $3(+++)$ & $\begin{array}{l}\text { Moderate gingivitis (red, swollen and } \\
\text { occasional bleeding) }\end{array}$ \\
\hline $4(++++)$ & $\begin{array}{l}\text { Severe gingivitis (red, swollen and profuse } \\
\text { bleeding) }\end{array}$ \\
\hline
\end{tabular}

regarded as negative control [8]. Group - 2: Animals were given normal food with provision of dental chew 
twice daily immediately after food [8]. Group - 3: Animals were given normal food and application of chlorhexidine on the buccal surface of the tooth by soaked cotton twice daily after food was done [15]. Group - 4: Animals were given normal food and provision of both dental chew and application of chlorhexidine on tooth surface done. Details of the experimental group assigned are given in Table-3.

\section{Dental chew}

Commercially available vegetable dental chew was used for the study. The chew had ingredients such as rice flour, soy protein concentrate, vegetable glycerine, cellulose, sodium hexametaphosphate, citric acid, chlorophyll, peppermint, parsley, natural flavor, and water (calorie $-2800 \mathrm{kcal} \mathrm{ME} / \mathrm{kg}$, crude protein $-20 \%$, Crude fat $-0.5-1.5 \%$, crude fiber $-4 \%$, and moisture $-15 \%$ ). The shape of the chew was spirally twisted around the vertical axis to increase the surface area for better cleansing action.

\section{Results and Discussion}

In 23 (71.87\%) and 11 dogs (34.37\%), the presence of plaque deposition and gingivitis was detected, respectively. Table-4 represents the plaque deposition score of the examined canines in relation to the age groups. This showed that with the increasing age of the animals, the plaque deposition increases on the surface of teeth. Higher incidence of periodontitis in pet dogs as high as $86 \%$ has been reported by many workers from time to time $[5,6,10,16]$. The outcome of the disease may have distant implications on the systemic organs [17].

When the plaque deposition score was plotted against the age of the screened animals, almost linear relationship (straight line) was obtained (Graph-1). The slope of the line obtained was $y=0.3621 \mathrm{x}+0.042$ with coefficient of determination $\left(\mathrm{r}^{2}\right)$ 0.7943. This signifies the fact that with the increase in age of the animals more or less a higher plaque deposition score can always be predicted. The value of the coefficient of correlation (r) came out to be $0.89(\mathrm{p}<0.05)$, suggesting a strong positive correlation between advancing age with increased risk of plaque deposition on the surface of tooth. The Pearson coefficient of correlation (r) between age and level of gingivitis in animals was found to be $0.67(p<0.05)$. Similarly, the relationship between plaque deposition score and subsequent gingivitis level came as $r=0.85(p<0.05)$. It was evident from the analysis of data that the development of gingivitis was dependent on both age and plaque deposition on the tooth surface. However, gingivitis was more dependent on the amount of plaque deposition than age. This was evident from the coefficient of determination $\left(r^{2}\right)$ score of age - gingivitis $\left(r^{2}=0.45\right)$ and plaque deposition score - gingivitis $\left(\mathrm{r}^{2}=0.73\right)$. Small dog breeds have been reported with more than $85 \%$ dentogingival alterations out of which periodontal disease, calculus, missing teeth, and abnormal attrition constitutes $60 \%, 61 \%, 33 \%$, and $5 \%$, respectively [5].
Similar findings in domesticated canines have been encountered by many authors $[4,8,10,16]$.

\section{Ultrasonic scaling}

After the scaling, the surface teeth were appeared to be smooth (Figure-3). The smoothness of the surface can aid in lower deposition of plaque due to the nonadherence of the bacterial biofilm. Ultrasonic scaling method was employed for removal of plaque and the animals were regarded as of clean mouth model for the experimental design. The supremacy of

Table-3: Experimental test groups.

\begin{tabular}{ll}
\hline Group-1 & $\begin{array}{l}\text { Normal food habit with no dental health care } \\
\text { Group-2 } \\
\text { chew }\end{array}$ \\
Group-3 & $\begin{array}{l}\text { Normal food habit with the provision of dental } \\
\text { gluconate }(0.20 \% \text { w/v }) \text { application BID after } \\
\text { food }\end{array}$ \\
Group-4 & $\begin{array}{l}\text { Normal food habit with both dental chew BID } \\
\text { and application of chlorhexidine gluconate } \\
(0.20 \% \mathrm{w} / \mathrm{v}) \text { BID }\end{array}$ \\
\hline
\end{tabular}

Table-4: Age-wise visible plaque deposition score.

\begin{tabular}{|c|c|c|c|c|c|}
\hline \multirow{2}{*}{$\begin{array}{l}\text { Age group } \\
\text { (Years) }\end{array}$} & \multicolumn{5}{|c|}{ Number of animals } \\
\hline & Score 0 & Score 1 & Score 2 & 2 Score 3 & Score 4 \\
\hline $0.5-1.5$ & 10 & 1 & $\mathrm{Nil}$ & $\mathrm{Nil}$ & $\mathrm{Nil}$ \\
\hline $2-3.5$ & Nil & 12 & 1 & Nil & Nil \\
\hline $4-6$ & $\mathrm{Nil}$ & 1 & 2 & 1 & $\mathrm{Nil}$ \\
\hline $8-10$ & Nil & $\mathrm{Nil}$ & $\mathrm{Nil}$ & 2 & 1 \\
\hline$>10$ & $\mathrm{Nil}$ & $\mathrm{Nil}$ & $\mathrm{Nil}$ & $\mathrm{Nil}$ & 1 \\
\hline
\end{tabular}

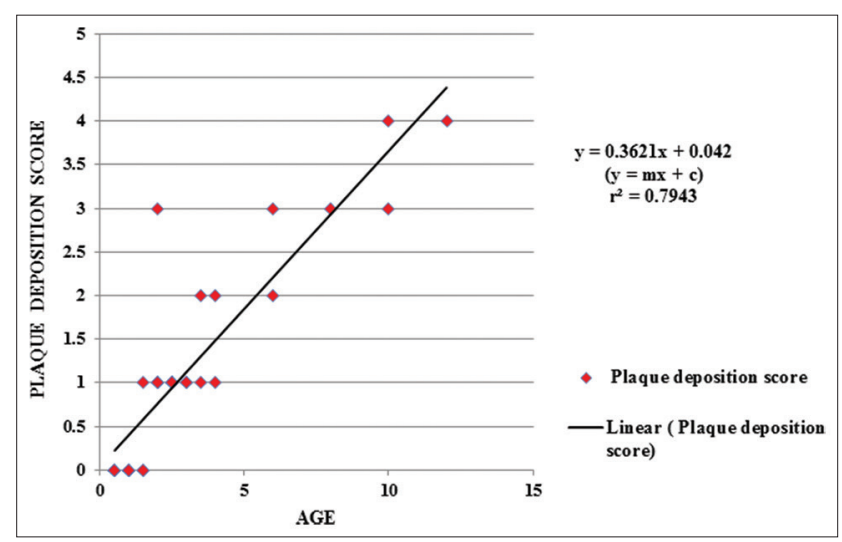

Graph-1: Age-wise plaque deposition score of the animals (X-axis: Age of the animal, Y-axis: Plaque deposition score).

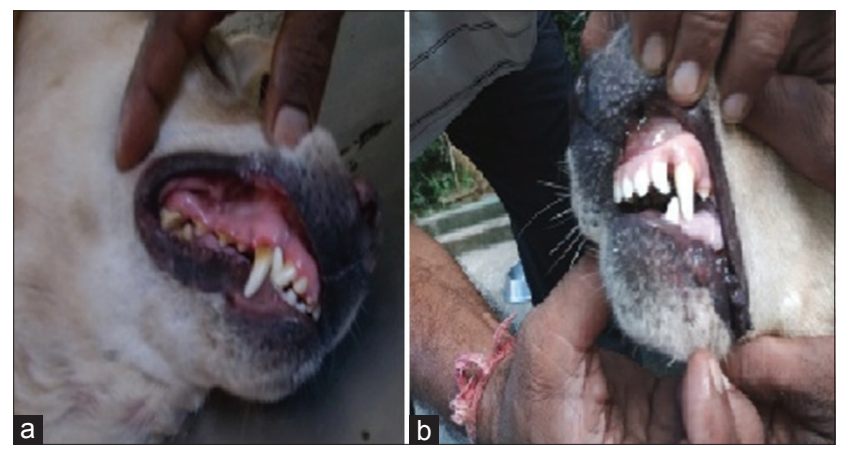

Figure-3: Effect of scaling of the tooth (a) before, (b) after. 
Table-5: Plaque deposition after the test period ( $28^{\text {th }}$ day).

\begin{tabular}{lccccc}
\hline Group & Dog no. & $\begin{array}{c}\text { Prior plaque } \\
\text { score }\end{array}$ & $\begin{array}{c}\text { Prior gingivitis } \\
\text { score }\end{array}$ & $\begin{array}{c}\text { Percentage of teeth surface } \\
\text { covered with plaque }\end{array}$ & $\begin{array}{c}\text { Percentage of } \\
\text { affected }\end{array}$ \\
\hline Group-1 & 1 & 4 & +++ & 15 & 50 \\
& 2 & 3 & + & - & \\
Group-2 & 3 & 1 & - & - & \\
& 4 & 1 & + & - & \\
& 5 & 3 & - & - & \\
Group-3 & 6 & 0 & - & - & \\
& 7 & 1 & - & - & \\
& 1 & 1 & + & 5 & \\
Group-4 & 10 & 1 & + & - & \\
& 11 & 2 & + & - & \\
& 12 & 2 & - & - & \\
\end{tabular}

mechanical methods like scaling for effective removal of plaque is also commensurate with the findings of previous researchers $[1,5,11,18-20]$.

\section{Experimental design}

The plaque deposition pattern of the dogs under experimental design was analyzed after $28^{\text {th }}$ day. The detailed result of the experimental design is depicted in Table-5.

At the end of the $28^{\text {th }}$ day period, it was found that the two dogs $(50 \%)$ of Group - 1 were shown prominent deposition of plaques on the tooth surface. In Group - 2, one dog (25\%) also showed deposition of plaques. The use of dental chew for abrasive clearance of plaque has been reported by many workers [8,21-23]. Previous reports also posited that dogs receiving the daily oral chew had significantly less dental calculus $(45.8 \%)$ and plaque accumulation $(17.3 \%)$ compared to the dogs not receiving the same [24]. Previous experimental findings on dental chew use also reported a reduction in mean gingival score by $11.25 \%$, affirming the findings of the present study [8]. Previous findings also reported the presence of sodium hexametaphosphate in the dental chew can aid in avoidance of plaque deposition [10].

Similarly, the observation was made in Group 3 . Two animals $(50 \%)$ receiving $0.20 \% \mathrm{w} / \mathrm{v}$ chlorhexidine application BID after food showed fresh plaque deposition. Effectiveness of chlorhexidine for control of plaque deposition and mouth cavity infections has been documented by many workers [25-27]. Group 4 having four animals with provision of both dental chew and chlorhexidine showed no plaque deposition after the $28^{\text {th }}$-day observation. The result confirmed the synergetic effects of both chemical and mechanical means of plaque removal to be most efficacious in nature.

From the result, it was observed that animals with prior high plaque deposition scores were more prone to reoccurrence of subsequent deposition. The risk can grow higher with no oral hygiene measures. The
Pearson coefficient of correlation (r) between prior plaque depositions (0 day) and subsequent plaque deposition $\left(28^{\text {th }}\right.$ day) after treatments was calculated to be $0.8(\mathrm{p}<0.05)$. This result can be explained by the fact that most of the new deposition started from the interdental spaces and periodontal space where cleaning by scaling was less efficient as compared to the table surface of the teeth. Even if prophylactic measures were undertaken, plaque already deposited at difficult sites (interdental spaces and periodontal spaces) may again start new depositions. The appearance of higher amount of fresh plaques without any control measures like in the control group has been reported by many workers $[8,11,12,24]$.

\section{Conclusion}

The present study gathered firm evidence on the presence of periodontal disease complex in the domestic canines due to food habits and lack of oral hygiene measures. The reduced effectiveness of chlorhexidine for control of plaque deposition compared to other test groups can be attributed to the fact that the effectiveness of the chemical was transient on the tooth surface due to licking movement of the tongue. The compounding effects of both chemical and mechanical means of plaque removal in the last group were found to be most effective. This can be ascribed to the fact that both the methods in combination were effective for control of oral hygiene in domestic canines.

\section{Authors' Contributions}

NG conducted the study and prepared the manuscript. MD and RCP designed the study and reviewed the manuscript prepared. SB and SKP supported the study and helped in the preparation of manuscript. All authors read and approved the final draft of the manuscript.

\section{Acknowledgments}

The authors are grateful to Dean, College of Veterinary Science and $\mathrm{AH}$, Orissa University of 
Agriculture and Technology for providing necessary facilities for the study. The authors did not receive any funds for this study.

\section{Competing Interests}

The authors declare that they have no competing interests.

\section{Publisher's Note}

Veterinary World remains neutral with regard to jurisdictional claims in published institutional affiliation.

\section{References}

1. de Lacerda, L.S. and Alessi, A.C. (2015) Effect of ultrasonic scaling of teeth involved with periodontal disease in dogs: A scanning electron microscopic study. Biosci. J., 31(5): 1488-1495.

2. Klein, T. (2008) Predisposing factors and gross examination findings in periodontal disease. Clin. Tech. Small Anim. Pract., 15(4): 189-196.

3. Do, M.J., Kim, K., Haeshin, L., Seho, C., Taegun, S., HeeJung, P., Jeong-Soon, L. and Tae, I.K. (2013) Development of animal experimental periodontitis models. J. Periodontal. Implant Sci., 43(4): 147-152.

4. Albuquerque, C., Morinha, F., Requicha, J., Martins, T., Dias, I., Guedes-Pinto, H., Bastos, E. and Viegas, C. (2012) Canine periodontitis: The dog as an important model for periodontal studies. Vet. J., 191(3): 299-305.

5. Adepu, R., Raghavender, K.B.P., Kumar, V.G. and Ramesh, N. (2018) A clinical study on the incidence of periodontal diseases in dogs and their surgical management. Pharm. Innov. J., 7(4): 290-292.

6. Kortegaard, H.E., Eriksen, T. and Baelum, V. (2008) Periodontal disease in research beagle dogs - an epidemiological study. J. Small Anim. Pract., 49(12): 610-616.

7. Niemiec, B.A. (2008) Periodontal disease. Top. Companion Anim. Med., 23(2): 72-80.

8. Clarke, D.E., Kelman, M. and Perkins, N. (2011) Effectiveness of a vegetable dental chew on periodontal disease parameters in toy breed dogs. J. Vet. Dent., 28(4): 230-235.

9. Niemiec, B.A. (2013) Periodontal therapy. Top. Companion Anim. Med., 23(2): 18-289.

10. Stella, J.L., Bauer, A.E. and Croney, C.C. (2018) A cross-sectional study to estimate prevalence of periodontal disease in a population of dogs (Canis familiaris) in commercial breeding facilities in Indiana and Illinois. PLoS One, 13(1): e0191395.

11. Bauer, A.E., Stella, J., Lemmons, M. and Croney, C.C. (2018) Evaluating the validity and reliability of a visual dental scale for detection of periodontal disease (PD) in non-anesthetized dogs (Canis familiaris). PLoS One, 13(9): e0203930.

12. Quest, B.W. (2013) Oral health benefits of daily dental chews in dogs. J. Vet. Dent., 30(2): 84-87.

13. Tranquilli, W.J., Thurmon, J.C. and Grimm, K.A. (2007) Lumb and Jones' Veterinary Anesthesia and Analgesia. $4^{\text {th }}$ ed. Blackwell Publishing Professional State Avenue, Ames, Iowa, USA.

14. Hennet, P., Servet, E., Soulard, Y. and Biourge, V. (2007) Effect of pellet food size and polyphosphates in preventing calculus accumulation in dogs. J. Vet. Dent., 24(4): 236-239.

15. Hamp, S.E., Lindhe, J. and Loe, H. (1973) Long term effects of chlorhexidine on developing gingivitis in the beagle dog. J. Periodont. Res., 8(2): 63-70.

16. Pavlica, Z., Petelin, M., Juntes, P., Erzen, D., Crossley, D.A. and Skaleric, U. (2008) Periodontal disease burden and pathological changes in organs of dogs. J. Vet. Dent., 25(2): 97-105.

17. Santos, J.D.P., Cunha, E., Nunes, T., Tavares, L. and Oliveira, M. (2019) Relation between periodontal disease and systemic diseases in dogs. Res. Vet. Sci., 125: 136-140.

18. Allan, R.M., Adams, V.J. and Johnston, N.W. (2019) Prospective randomized blinded clinical trial assessing effectiveness of three dental plaque control methods in dogs. J. Small Anim. Pract., 60(4): 212-217.

19. Schiffner, U., Bahr, M. and Effenberger, S. (2007) Plaque and gingivitis in the elderly: A randomized, single-blind clinical trial on the outcome of intensified mechanical or antibacterial oral hygiene measures. J. Clin. Periodontol., 34(12): 1068-1073.

20. Fichtel, T., Crha, M., Langerová, E., Biberauer, G. and Vla, M. (2008) Observations on the effects of scaling and polishing methods on enamel. J. Vet. Dent., 25(4): 231-235.

21. Marx, F.R., Machado, G.S., Pezzali, J.G., Marcolla, C.S., Kessler, A.M., Ahlstrom. and Trevizan, L. (2016) Raw beef bones as chewing items to reduce dental calculus in Beagle dogs. Aust. Vet. J., 94(1-2): 18-23.

22. Nuttall, D., Butterwick, R., Strauhs, K. and McGenity, P. (2017) Comparison of measured and predicted energy density of an oral care chew for dogs. J. Nutr. Sci., 6(e29): 1-3.

23. Harrision, C. (2017) Nutrition and preventative oral healthcare treatments for canine and feline patients. Vet. Nurse, 8(8): 432-440.

24. Hennet, P., Servet, E. and Venet, C. (2006) Effectiveness of an oral hygiene chew to reduce dental deposits in small breed dogs. J. Vet. Dent., 23(1): 6-12.

25. Pulcini, A., Bollaín, J., Sanz-Sánchez, I., Figuero, E., Alonso, B., Sanz, M. and Herrera, D. (2019) Clinical effects of the adjunctive use of a $0.03 \%$ chlorhexidine and $0.05 \%$ cetylpyridinium chloride mouth rinse in the management of peri-implant diseases: A randomized clinical trial. J. Clin. Periodontol., 46(3): 342-353.

26. Dameski, V., Vnuk, D., Habrun, B. and Kompes, G. (2018) Antiseptic efficacy of chlorhexidine and povidone-iodine rinsing lingual mucous membrane in dogs. Vet. Stanica, 49(3): 159-167.

27. Torkan, S. (2015) Comparison of the effects of an herbal mouthwash with chlorhexidine on surface bacteria counts of dental plaque in dogs. Biosci. Biotechnol. Res. Asia, 12(1): 955-959. 